\title{
II. EL RÉGIMEN POLÍtICO PERUANO
}

\section{GUILLERMO MALDONADO}

Universidad Católica de Lima 


\section{SUMARIO}

I. Evolución histórica de las Constituciones del Perú.-A. Los primeros ensayos de organización constitucional (1823-1856). B. Las Constituciones modernas: de la Constitución de 1920 al Gobierno Revolucionario de las Fuerzas Armadas (1968-80). II. FORMULACIÓN IDEOLÓGICO-POLITICA Y NOTAS CARACTERISTICAS DEL RÉGIMEN POLITICO PERUANO EN LA CONSTITUCIÓN DE 1979.-III. ESTRUCTURA E INSTITUCIONES POLITICAS FUNDAMENTALES.-1. EI Parlamento.-A. Composición de las Cámaras. B. Organización y funcionamiento. C. Funciones del Parlamento. 2. El Presidente de la República.-A. Elección del Presidente de la República. B. Finalización del mandato presidencial. C. Atribuciones del Presidente de la República. 3. El Consejo de Ministros.A. Composición. B. Nombramiento. C. Atribuciones.-IV. LA DESCENTRALIZACIÓN POLITICA.-A. Los gobiernos locales. B. Los gobiernos regionales.-V. El Tribunal de Garantías ConstitucioNALES.-A. Composición. B. Competencias.-VI. SITUACION ACTUAL DEL RÉGIMEN PERUANO. 
Revista de Derecho Político, núm. 33, 1991, pp. 391-426

\section{EL RÉGIMEN POLÍTICO PERUANO}

POR

GUILLERMO MALDONADO

Universidad Católica de Lima

\section{EVOLUCIÓN HISTÓRICA DE LAS CONSTITUCIONES DEL PERÚ}

\section{A. LOS PRIMEROS ENSAYOS DE ORGANIZACIÓN CONSTITUCIONAL (1823-1856)}

La historia republicana del Perú se ha caracterizado por la abundancia de Constituciones, la mayor parte de ellas de efímera duración. Tomando en cuenta el número total, observamos que ha existido una carta política por cada tres lustros de vida independiente. Debemos precisar, sin embargo, que el mayor número de textos vieron la luz en el siglo xIX, existiendo una relativa estabilidad constitucional a partir de 1860 '.

La abundante producción constitucional de los primeros decenios de la República, así como el hecho de que tuvieran una vida efímera o escasa vigencia real, no deja dudas sobre la inconveniencia de un análisis exegético que, por otro lado, olvidaría un dato fundamental para la comprensión del tema en el Perú: "La historia de la práctica constitucional del país muestra el constraste entre la Constitución "formal" y la Constitución "real" 2. Por consiguiente, y atendiendo al objeto de nuestro estudio, pon-

1 En dicho período histórico existieron los siguientes textos políticos: El Reglamento y el Estatuto provisorio de San Martín de 1821, las Bases de la Constitución Política de la República Peruana, las Constituciones de 1823, 1826, 1828 y 1834, las Constituciones del Estado Nor Peruano y Sur Peruano de 1836, la Constitución de los Estados Nor, Sur Peruano y Bolivia de 1837, la Constitución de Huancayo de 1839, el Estatuto Provisorio de 1855, las Constituciones de 1856, 1860 y 1867, asi como el Estatuto Provisorio de 1879.

2 Rubio, Marcial, y Bernales, Enrique: Constitución y Sociedad Política. Lima, Mesa Redonda Editores, 1985, pág. 17. 
dremos de relieve aquellos aspectos que tendrán una mayor influencia en la formación del régimen político peruano.

El proceso de formación del Estado y de la Nación peruano se halla aún inconcluso ${ }^{3}$. Su origen se inscribe dentro de un largo período de anarquia, caudillismo y militarismo, con guerras internacionales y civiles constantes, generando una caracteristica inestabilidad política. Ante semejante realidad política, la excesiva preocupación por diseñar textos constitucionales de acuerdo a los principios y modelos teóricos -especialmente liberales-, propició la irrealidad de sus postulados y, por tanto, su escasa o nula vigencia. Se discutió en torno a la construcción de sistemas políticos basados sobre conceptos de un Estado-Nación producto de la experiencia histórica de Europa, pero inexistente en el Perú. Los ideólogos criollos se sumian en el estudio de las teorias políticas europeas y norteamericanas para su posterior instalación en el Perú, soslayando las características que separan estas realidades. Como acertadamente resume PAREJA PAZ SOLDẢN, «la República fue una creación política, lo que no existia se inventó» ${ }^{4}$.

La Constitución de Cádiz de 1812 constituye el antecedente fundamental de la historia constitucional de la América hispana. Es significativo que en la doctrina peruana existan posiciones que sostengan que se trata de una Carta Política nacional ${ }^{5}$. Su influencia en el Perú, pese a su corta vida, será duradera; el reconocimiento del principio de igualdad ${ }^{6}$, de la

3 Sobre este tema polémico puede consultarse a COTLER, Julio: «La construcción nacional en los paises andinos», Revista de Pensamiento Iberoamericano, núm. 6, Madrid, Instituto de Cooperación Iberoamericano, 1985, págs. 119 y ss.

4 "No habíamos tenido ni una aristocracia territorial, ni una minoría experta en el arte del gobierno, ni tradiciones constitucionales, ni pleno goce de libertades, ni la experiencia adquirida en el gobierno local, como habia ocurrido en las colonias norteamericanas o en Chile. Fue necesario inventar todo eso dentro de un orden nuevo. De allí la profusión de nuestros textos constitucionales». PAREJA PAZ SOLDÁN, José: Las Constituciones del Perú. Madrid, Ediciones Cultura Hispánica, 1954, página 89.

5 La mayor parte reconoce la influencia de esta Constitución, pero no la considera nacional, dado que fue promulgada antes de la independencia y de la creación del Estado peruano. El Dr. Ugarte del Pino es el más destacado defensor de la tesis opuesta, al sostener que «la inclusión de la Constitución de 1812 se justifica como una Constitución nuestra, por haber sido discutida artículo por articulo y votada por diputados peruanos... y por haber sido jurada y promulgada en Lima $y$ en todos los pueblos del Perú, con todas las formalidades de la época, incluso haberse efectuado elecciones municipales y nombramiento de autoridades conforme a ella". Ugarte del Pino, Juan Vicente: Historia de las Constituciones del Perú. Lima, Editorial Andina, 1978, pág. 31.

6 El logro no se redujo a reconocer la igualdad entre americanos y españoles, sino que habria de extenderse a importantes derechos para los indigenas y negros, así como el voto para los analfabetos. En estos puntos hubo una especial participación de los representantes peruanos. UGARTE DEL PINO, J. V.: Historia de las Constituciones..., op. cit., pág. 32. 
soberanía popular nominal (sustituyendo a la soberanía como atributo del rey) y de la división de poderes, serán los cimientos de las Cartas republicanas. En lo sucesivo el Parlamento no representaria a los estamentos -clero, nobleza y burguesía-, sino a la Nación. La Constitución se presenta, pues, como una conquista.

El debate sobre el sistema político que debería regir en el Perú se inicia años antes de lograr la efectiva independencia de España ${ }^{7}$. La posibilidad de una salida monárquica y no republicana fue impulsada por el libertador San Martín entre 1820 y 1822. Tal postura quedó plasmada en el Reglamento y Estatuto Provisorios ${ }^{8}$, "su objeto era simplemente resguardar los avances de la insurrección libertadora y preparar al pais para el gobierno de uno solo, que bien pudo ser un monarca» '. San Martín fracasó ${ }^{10} \mathrm{y}$, ante su debilitada posición militar y la presión de Bolívar desde Guayaquil ${ }^{11}$, se vio en la necesidad de convocar a un Congreso Constituyente y dejar en manos de éste la tarea de gobierno.

El alejamiento de San Martín puso fin al debate monárquico. Desde 1823 el escenario ideológico sería ocupado por la lucha entre las fórmulas liberal y conservadora, entre el sistema parlamentario y autocrático 0 , visto desde otra perspectiva, entre la tendencia federal y unitaria.

Se puede afirmar que los debates ideológicos entre los congresistas durante este periodo terminaron generalmente en una victoria liberal, impregnando con sus ideas el contenido de las Constituciones de 1823, 1828, 1834, 1856 y 1867. Si la Constitución formal es de orientación liberal, la organización política real se regirá negando, precisamente, estos prin-

7 La Declaración de Independencia se lleva a cabo en Lima el 28 de julio de 1821, pero es sólo en 1824, con las victorias militares en Junín y Ayacucho, cuando se logra el reconocimiento español de la independencia del Perú.

8 Todos los textos políticos a los que haremos referencia en este capítulo pueden ser consultados en la ya citada obra de UGARTE DEL PINo, J. V.: Historia de las Constituciones del Perú.

- Alzamora Silva, Lizardo: La evolución politica y constitucional del Perú independiente. Lima, Imprenta Gil, 1942, pág. 23.

${ }_{10}$ El fracaso de San Martín también comprende las negociaciones con autoriades españolas para establecer una monarquía autóctona, previo reconocimiento de la independencia del Perú. Véase BASADRE, Jorge: La iniciación de la República, tomo I, Lima, Librería Francesa y Casa Editorial Rosay.

1 El dato de la gran extensión territorial fue motivo para proponer una autoridad real o monárquica o bien un sistema federativo. Bolívar destacó la imposibilidad de aplicar la solución monárquica "en una región constitutivamente democrática», afirmando luego que el gobierno federal es «una anarquía organizada...; el gobierno norteamericano podrá ser el mejor del mundo, pero la experiencia de su imitación más al sur — se refiere a Buenos Aires, Chile, México y Guatemalaha sido desastrosa». Véase la carta de Bolivar a Oleary, en Bolivar, Simón: Obras Completas, vol. II, La Habana 1947, págs. 771 y ss. 
cipios. En la medida que el radicalismo liberal es abandonado, las posibilidades de una vigencia constitucional afectiva se acrecienta. Por esta misma razón, como veremos más adelante, las Constituciones conservadoras logran mayor éxito, al regular efectivamente parcelas importantes de la organización política por un lapso mucho mayor.

La primera Constitución del Perú se aprobó en 1823 y con buen juicio ha sido calificada como «una solemne ficción» ${ }^{12}$. Establece que «todas las provincias del Perú, reunidas en un solo cuerpo forman la Nación peruana", en donde «la soberanía reside esencialmente», anotando que el gobierno es "popular y representativo". Su afecto a la doctrina roussoniana queda plasmado en su artículo 40, donde se lee: «Si la Nación no conserva o protege los derechos legítimos de todos los individuos que la componen, ataca el pacto social; asi como se extrae de la salvaguardia de este pacto cualquiera que viole alguna de las leyes fundamentales».

Los derechos de la persona también ocupan un lugar privilegiado: «La Nación no tiene facultad para decretar leyes que atenten a los derechos individuales". Sigue radicalmente la doctrina de separación de poderes de Montesquieu de modo que, luego de reconocer los poderes Legislativo, Ejecutivo y Judiciario, consigna que «ninguno de los tres poderes podrá ejercer jamás ninguna de las atribuciones de los otros dos" ${ }^{13}$. En plena campaña militar, el Congreso otorga plenos poderes al libertador Bolívar, dejando en suspenso la Constitución. Se sacrifican los postulados democráticos consignados en la Carta por la urgencia de la independencia.

La Constitución de 1828, de esencia liberal como su predecesora, exhibe, sin embargo, diferencias fundamentales que la convierten en una de las más equilibradas de dicho siglo. Logra una armónica distribución de poderes y establece algunas formas de organización política que serán mantenidas posteriormente: régimen presidencial, con un Presidente dotado de amplios poderes y cuya responsabilidad es compartida con los ministros, quienes deben refrendar obligatoriamente los decretos y órdenes del gobierno; elección popular del Jefe de Estado; bicameralidad del Parlamento; inamovilidad de los miembros del Poder Judicial y unión del Estado y la Iglesia ${ }^{14}$.

12 Alzamora Silva, L.: Evolución..., op. cit., pág. 25.

13 Con anterioridad en las Bases de la Constitución, aprobadas en diciembre de 1822 , se señalaba que «el principio más necesario para el establecimiento y conservación de la libertad era la división de los tres poderes haciéndolos independientes de cuanto fuera dable».

${ }_{14}$ Es significativo que tanto las Cartas liberales como conservadoras plantearon la unión del Estado con la Iglesia católica, y, en no pocos casos, hayan proscrito otros cultos. 
La Constitución de 1828 logró regir, aunque debió soportar el gobierno autoritario de Gamarra. Dado que estaba previsto que dos años después se convocara una Asamblea para su modificación total o parcial, la Convención Nacional aprobó la Constitución de 1834, siguiendo el talante liberal de su predecesora.

Influenciada por el problema político de la sucesión pesidencial, este texto exhibe las huellas de las luchas civiles previas contra el despotismo de Gamarra y sus seguidores, así como el desprestigio de la oligarquía militar en el poder. Por ello, su principal característica es su antimilitarismo, plasmado en la limitación de los grados militares, la determinación de sus efectivos y la ratificación de los ascensos por el Parlamento, así como la incompatibilidad de ejercer la Presidencia y el mando de las Fuerzas Armadas. Otro aspecto destacable, además de la supresión de las Juntas Departamentales, es el levantamiento de la prohibición de federales, lo que posibilitaría la unión con Bolivia y las funestas consecuencias para el Perú ${ }^{15}$.

De todas las Constituciones liberales destaca la aprobada en 1856. El ejemplo de las jornadas europeas de 1848 despertó una polémica sumamente ideologizada entre conservadores y liberales cuya máxima expresión será la Constituyente de 1855 , aunque su influencia alcanzaría incluso a la Constituyente de 1860 . Se pretendió lograr la república modelo con un renovado fervor doctrinario, perdiendo los lazos con la realidad peruana. Sus principales aspectos fueron los que concitaron mayor oposición; el debilitamiento de las facultades del Poder Ejecutivo en beneficio del Parlamento, la creación del Consejo de Ministros como copartícipe del Ejecutivo, la supresión del fuero eclesiástico y de la patrimonialidad de los empleos públicos, la inamovibilidad del Poder Judicial, la ratificación de los ascensos militares y el restablecimiento de las Juntas Departamentales y de las Municipalidades.

Atacada por los sectores militares, eclesiásticos y burocráticos a los que afectó con sus reformas, la Carta liberal de 1856 tuvo un brusco final con el golpe de Estado de 1860. El mismo año, la Asamblea ordinaria convocada asume competencias constituyentes y sanciona una nueva Constitución.

La Constitución de 1860 posee como virtud principal su larga vida ${ }^{16}$ —rigió hasta 1920 - alejando las dictaduras y caudillajes militares de viejo

15 La llamada Confederación Perú-Boliviana dividió en dos el territorio peruano y provocaría una guerra fratricida con Chile y Argentina. Véase BASADRE, Jorge: Historia de la República del Perú, tomo I, Lima 1940, capitulos V al VII.

${ }_{16}$ Una revolución pondría en vigencia una Constitución en extremo liberal, la de 1867; no obstante, pocos meses después una nueva insurrección, esta vez conservadora, pondría nuevamente en vigencia la Carta de 1860. 
cuño, aunque permitió la instalación de una oligarquía «civilista» y la presencia de no pocos fraudes electorales.

Corrigiendo los «excesos» liberales previos, marginó a los analfabetos e impuso el voto censitario e indirecto; la elección por provincias y departamentos de los diputados y senadores propició la formación de un caciquismo electoral; fortaleció la figura presidencial como reacción al parlamentarismo arrogante de 1856; el Congreso, organizado bicameralmente, perdió atribuciones de control sobre el Presidente de la República, como la acusación ante el Senado por infracción de la Constitución; las sesiones congresales serían bianuales en vez de anuales, creando la figura de la Comisión Permanente del Cuerpo Legislativo con diversas funciones, entre las que destaca la de vigilar al Ejecutivo.

Las reformas que afectaron a la iglesia, al sector militar y a los empleados públicos perdieron vigencia. Fue, finalmente, una Constitución centralista que relegó a un segundo plano el poder municipal e ignoró las Juntas Departamentales. Es con esta Carta con la que se ingresa en el siglo $x x$.

La Constitución de 1826, más conocida como la Constitución Vitalicia, fue una creación de Bolivar y constituyó el primer ensayo conservador en el Perú. Está emparentada con la etapa en la que el libertador propone un «cesarismo semifederal y semidemocrático, de incuestionable influencia napoleónica» ${ }^{17}$. El fracaso de esta Carta queda manifiesto en sus siete semanas de vigencia; no obstante, tiene importancia como expresión de la búsqueda de una salida que conciliara la Monarquia y la República, en un afán de poner término al caos y la arbitrariedad.

El segundo intento conservador tendría lugar en 1839 , con la denominada Constitución de Huancayo. La anarquía generada durante la Confederación Perú-Boliviana produjo una reacción autoritaria y centralista que quedó plasmada en sus preceptos. Como ha sido apuntado “adoptó definitivamente la politica del orden ante todo» ${ }^{18}$. Se redactó un texto sencillo, sin demasiada preocupación doctrinal, buscando la estabilidad; bastó un Poder Ejecutivo fuerte, la supresión de las Municipalidades, pocas asambleas y nada de politica. Las deficiencias doctrinales fueron equilibradas por una vigencia sin precedentes, pues se mantuvo hasta 1855.

17 Además de un presidente vitalicio, el Poder Legislativo, a semejanza de la Constitución napoleónica, está compuesto por tribunos, senadores y censores. Véase BELAÚNDE, Víctor Andrés: Bolívar y el pensamiento político de la revolución hispanoamericana. Madrid 1959, pág. 137.

18 Véase Pareja Paz Soldán, J.: Derecho Constitucional..., op. cit., pág. 11. 
B. Las ConstituCIONES MOdERNAS: DE LA CONSTITUCION DE 1920 aL GoBIERNO REVOLUCIONARIO DE LAS FUERZAS ARMADAS (1968-80)

La Carta de 1860 , atravesando crisis políticas y breves interrupciones ${ }^{19}$, mostró una mayor adaptación a la difícil realidad peruana, sustentándose en un modelo transaccional, ni conservador ni liberal en extremo, inspirado en la división de poderes, la soberanía popular, el Ejecutivo y el Parlamento elegidos por el pueblo, un Ejecutivo fuerte en lo personal pero limitado en su acción de control e iniciativa económica ${ }^{20}$.

Sin embargo, fueron muchos años de sucesivos gobiernos oligárquicos, periodo denominado de la «república aristocrática», los que erosionaron su legitimidad. Por otro lado, se habia entrado en un nuevo siglo que deparó transformaciones en todos los órdenes. El debate liberal-conservador habia sido superado y en su reemplazo ingresan las tendencias socializadoras promovidas por movilizaciones obreras y estudiantiles, además del influjo de Constituciones como la mexicana de 1917, la bolchevique de 1918 y la alemana de Weimar de 1919.

Dentro de este marco se gesta la revolución de 1919, que llevaría al poder a Augusto B. Leguía hasta 1930. El proyecto de una "Patria Nueva" precisaba de una nueva Constitución y ésta se aprobaría con la singularidad de someter los puntos básicos de la reforma a un plebiscito constituyente ${ }^{21}$. Dentro de la Constitución de 1920 destaca el retorno a la elección directa y coetánea del Presidente de la República, los senadores y los diputados; la facultad del Congreso para elegir el sucesor a la Presidencia en caso de muerte o dimisión; la creación de tres Parlamentos o Legislaturas regionales (Norte, Centro y Sur), con representantes elegidos en igual forma y fecha que los nacionales; la prohibición de que las garantías individuales fueran suspendidas por ley o autoridad alguna y, finalmente, la inclusión de un extenso capítulo dedicado a las garantías sociales.

Las saludables reformas que presentaba la Carta de 1920 no surtieron mayor efecto, merced al "oncenio" de Leguía que, si bien supuso una gran labor de modernización del Estado y políticamente expresó por vez primera a las clases medias, fue un régimen dictatorial y personalista que sólo tendría fin con una nueva revolución en 1930 al mando del comandante Sánchez Cerro.

19 Además de la mencionada Constitución liberal de 1867, durante la Guerra del Pacífico regiría el Estatuto de Piérola (1879-81) y ocurrirían diversas crisis políticas, destacando el intento de reforma constitucional de 1895.

20 Pareja Paz Soldán, J.: Derecho Constitucional..., op. cit., pág. 109.

21 Entendido como la versión autoritaria del referéndum democrático. Véase De Vergonttinı, Giuseppe: Derecho Constitucional Comparado. Madrid, Espasa-Calpe, 1983, pág. 153. 
Los excesos y arbitrariedades del régimen de Leguía arrastraron al descrédito la Carta de 1920, razón por la cual la Junta Nacional de Gobierno convocó elecciones para una Asamblea Constituyente, que también tendría atribuciones de Congreso ordinario. Sánchez Cerro, líder de la revolución de Arequipa, enarbolando lemas tradicionales y con el apoyo de las clases oligárquicas y la burguesía conservadora -además de una importante base popular rural-, logró una cuestionada y apretada victoria sobre Víctor Raúl Haya de la Torre, candidato y jefe indiscutido de la Alianza Popular Revolucionaria Americana (APRA), primer partido político de masas con ideología propia - basada en la alianza de las clases medias y el proletariado- y una eficiente organización similar a la europea, cuya influencia a nivel nacional y latinoamericano se mantiene hasta la actualidad.

Es particularmente importante la labor de la Comisión encargada de elaborar un anteproyecto de Constitución. El denominado proyecto Villarán ${ }^{22}$, elaborado con criterios técnicos y autónomos, fue superior en su contenido a la Constitución de 1933. En palabras de Basadre, «se preocupó, de modo cuidadoso y esforzado, en la organización de un Poder Judicial autónomo, libre de influencia política en los nombramientos. Creó la Comisión Permanente del Congreso, Consejos Consultivos permanentes, Consejo Nacional de Administración, el régimen de lo contencioso-administrativo, el Fiscal de la República. Otorgó gran vigor a la Contraloria General. Entregó a la Corte Suprema la facultad de declarar la inconstitucionalidad de las leyes. Tendió a la despolitización, a la racionalización, a la tecnificación y a la modernización del aparato del Estado».

La intensa lucha política exhibida durante las elecciones se trasladó a la Asamblea Constituyente de $1931^{23}$. La numerosa representación aprista defendia, con singular sustento doctrinal, proposiciones revolucionarias para el momento histórico. Posteriormente el levantamiento aprista de 1932 en Trujillo, la prisión o deportación de los representantes de dicho partido y la suspensión indefinida de las garantías individuales, propició el asesinato del Presidente Sánchez Cerro. La Asamblea, al consentir las medidas adoptadas contra los representantes apristas, quedó sin oposición ni legitimidad, así fue finalmente aprobada la Carta de 1933.

La Constitución de 1933 crea un régimen hibrido presidencial-parlamentario que provocó serios problemas políticos a gobiernos con un Parlamento adverso ${ }^{24}$. La propuesta aprista de un Parlamento unicameral no tuvo éxito y se creó un Senado funcional de corte corporativo que nunca

22 Véase Villarán, Manuel Vicente: Anteproyecto de Constitución de 1931, Lima, Talleres Gráficos P. L. Villanueva, 1962.

${ }^{23}$ Sobre el tema véase BALBI, Carmen Rosa, y MAdalengoitia, Laura: Parlamento y lucha política. Perú 1932, Lima, DESCO, 1980.

${ }_{24}$ Este fue el caso del Gobierno del Presidente Bustamante y Rivero (194548) y Belaúnde Terry (1963-68). 
llegó a constituirse ${ }^{25}$. El Presidente de la República es el Jefe de Estado y personifica a la Nación. El Consejo de Ministros tiene su propio presidente - primer ministro o premier - que debe otorgar su consentimiento para que el Presidente de la República pueda nombrar o remover a los ministros $y$, de otro lado, todo acto presidencial de gobierno precisa de la correspondiente refrendación ministerial.

Se establecieron una serie de controles sobre el Poder Ejecutivo. En este sentido, los ministros - que pueden ser parlamentarios a la vezpueden ser citados al Parlamento para ser interpelados o censurados, debiendo dimitir en el último caso. Tras la conformación de un nuevo gabinete ministerial, el primer ministro debe exponer ante el Congreso la política general del Gobierno. El Congreso puede crear Comités de Investigación Parlamentaria. Se suprimió todo tipo de veto presidencial sobre las leyes, se prohibió la reelección inmediata del Presidente de la República y se estableció la responsabilidad solidaria del Consejo de Ministros por actos delictuosos o infractorios de la Constitución o las leyes, aprobados en sesión de gabinete o cometidos por el Presidente de la República.

La mayoría de estas restricciones colisionaron con la terca tradición presidencialista, de modo tal que, por ejemplo, la designación de los ministros y el veto sobre las leyes siguió de hecho en manos del Presidente de la República. El primer ministro sólo era el primero entre iguales.

El Poder Judicial debió soportar un sistema de nombramientos en manos del Poder Ejecutivo, vio mermada su capacidad para inaplicar leyes inconstitucionales ${ }^{26}$ y careció de la jurisdicción contencioso-administrativa que propugnó el proyecto Villarán.

Se reconoció como un cuarto poder al electoral, lo que luego mereció severas críticas ${ }^{27}$, y creó el Registro Electoral Permanente. Se extendió el derecho de sufragio a las mujeres para las elecciones municipales ${ }^{28}$, marginando a los analfabetos, miembros de la fuerza armada y menores de veintiún años. La base electoral departamental se reguló por ley, dado que la Constitución guardó silencio al respecto.

Durante el gobierno del general Benavides, hacia 1939, se aprobó un plebiscito que, modificando o suprimiendo preceptos constitucionales, pretendia fortalecer el Poder Ejecutivo en detrimento de las atribuciones «excesivas" del Parlamento. Tales reformas fueron totalmente abolidas en diciembre de 1945 por la Ley de 1934.

${ }^{25}$ Véase sobre este punto Bernales, Enrique: La estructura del Parlamento, Lima, Pontificia Universidad Católica del Perú, 1970.

${ }^{26}$ Error corregido por el Código Civil de 1936.

${ }_{27}$ Rubio, M., y Bernales, E.: Constitución..., op. cit., pág. 305.

28 Posteriormente, la Ley 12391, de 7 de septiembre de 1951, otorgaría este derecho para las elecciones generales. 
A lo largo de sus cuarenta y seis años de vida - la segunda Carta de mayor duración después de la de 1860-, el sistema híbrido recogido por la Constitución de 1933 provocó disfunciones en las relaciones de los poderes, hechos que no lograron modificar la tendencia presidencialista que tradicionalmente orienta al régimen político peruano.

El primer gobierno de Belaúnde, en constante pugna con un Parlamento controlado por sus opositores políticos, será depuesto el 3 de octubre de 1968, antes de terminar con el mandato constitucional, por un golpe de Estado de las fuerzas armadas al mando del general Juan Velasco Alvarado.

La actuación del Gobierno Revolucionario de las Fuerzas Armadas -que denota su carácter institucional- ha ocasionado durísimas críticas y apasionadas defensas pero, por encima de ello, constituye un período de reformas estructurales de especial importancia para comprender el proceso político actual y es el antecedente directo de la Constitución de 1979.

Durante la denominada "Primera Fase" del Gobierno Militar ${ }^{29}$, se manifiesta el carácter original de este movimiento que, dejando la tradicional identificación con la clase conservadora, se presenta con reformas estructurales progresistas que alteran el panorama sociopolítico del Perú.

Mediante la reforma agraria - reconociendo todos los errores que pudo contener - se desplazó definitivamente del poder a la oligarquía terrateniente ${ }^{30}$. La actividad planificadora y la intervención directa del Estado en la economía del país se acrecentó de forma importante, acompañada de nacionalizaciones de empresas de sectores reconocidos como básicos o estratégicos, especialmente mineros, y la creación o desmembración de ministerios. Se otorgó a los trabajadores la participación en la gestión, utilidad y propiedad de las empresas industriales, se creó una nueva forma de propiedad denominada "Propiedad Social», se hicieron reformas en la educación y universidades, etc.

La movilización y cambio social se proyectó en lo político, propiciando el auge de las tendencias de izquierda. Se legaliza el proscrito Partido Comunista prosoviético y la Confederación General de Trabajadores del Perú (CGTP) -la más importante del país- de la misma tendencia, los que brindarán apoyo al Gobierno. Defendió la tesis del «no partido», promoviendo la movilización y apoyo popular «desde arriba».

29 El general Velasco se mantendría en el poder durante siete años, luego el general Morales Bermúdez asumió la Presidencia de la República cambiando la orientación revolucionaria del Gobierno y, finalmente, convocó la Asamblea Constituyente de 1978.

30 Véase PEASE, Henry: El ocaso del poder oligárquico, Lima, DESCO 1986. 
Los importantes cambios políticos y sociales operados desde 1933, muy en especial los ocurridos durante el gobierno del general Velasco, harán necesaria una nueva Carta y serán, a su vez, el marco de referencia para la Asamblea Constituyente de 1978, cuya composición política, como veremos más adelante, muestra un renovado rostro electoral y es indicativo del cambio cualitativo ocurrido en la sociedad peruana.

\author{
II. FORMULACIÓN IDEOLÓGICO-POLITICA Y NOTAS \\ CARACTERISTICAS DEL RÉGIMEN POLITICO PERUANO EN LA \\ CONSTITUCIÓN DE 1979
}

La Constitución peruana de 1979 se inscribe dentro de la corriente del "constitucionalismo social" que, bajo la influencia de la Constitución mexicana de 1917 y la alemana de Weimar de 1919, se inicia en el Perú con la Carta de 1920 y avanza en el bosquejo de una democracia social en la Constitución de $1933^{31}$. Dicha tendencia se verá reforzada por los cambios socioeconómicos producidos durante el gobierno del general Velasco.

Una primera apreciación de tipo formal nos remite a la notable extensión del texto constitucional. Se compone de 306 artículos, una disposición final y 18 disposiciones generales y transitorias, distribuidas en ocho títulos: de los derechos y deberes fundamentales de la persona, del Estado y de la Nación, del régimen económico, de la estructura del Estado, de las garantías constitucionales, de la reforma de la Constitución, y los dos últimos referidos a la disposición final y las disposiciones transitorias.

Por otro lado, la Constitución dispone un procedimiento parcialmente agravado para su reforma. Conforme al artículo 306 , se precisan dos votaciones -ambas en la primera legislatura ordinaria de años sucesivos-, bastando reunir la mayoría absoluta de votos del número legal de miembros de cada Cámara. Como un tímido asomo de participación semi-directa, 50.000 ciudadanos pueden intentar la reforma. No procede para estos casos la observación presidencial.

Es significativa la amplitud de muchas de sus formulaciones y la diversidad de interpretaciones o lecturas de la que es susceptible. Si bien no puede afirmarse categóricamente que se trata de una Constitución consensuada - la importante representación de grupos de izquierda no la firmaron-, en cambio sí exhibe los aportes provenientes de la peculiar conformación política de la Asamblea Constituyente de 1978. De un total de 100

31 Véase Ferrero, Raúl: Ciencia Politica. Lima, Studium, 1979, págs. 351 y ss. 
miembros, 37 fueron del Partido Aprista (socialdemócrata), 15 del Partido Popular Cristiano (conservador) y 28 correspondieron a diversas agrupaciones de izquierda ${ }^{32}$.

Tomando como referencia diversos artículos de la Carta ${ }^{33}$, se puede enumerar sintéticamente las notas características del régimen político peruano del modo siguiente: a) es unitario, descentralizado básicamente en regiones; b) es democrático y representativo; $c$ ) es republicano con un sistema híbrido, ni parlamentario ni presidencialista; d) es pluralista, reconoce y garantiza los derechos del hombre individual o colectivamente, plasmados en diversas facetas: económica (art. 112), política (art. 68), lingüística (art. 83), religiosa (art. 86); e) es social, según el artículo 79, basado en el trabajo, reconociendo los derechos económico-sociales y, sin la brillantez del artículo 3.2 de la Constitución italiana de 1947, establece en el artículo 80 como deberes primordiales del Estado «promover el bienestar general basado en la justicia y en el desarrollo integral y equilibrado del país, y eliminar toda forma de explotación del hombre por el hombre y del hombre por el Estado»; f) no es confesional, reconoce la importancia de la religión católica en la formación histórica del Perú, pero puede colaborar en semejantes condiciones con otras confesiones; $g$ ) propugna la integración latinoamericana y rechaza toda forma de imperialismo, colonialismo o neocolonialismo y discriminación racial.

\section{ESTRUCTURA E INSTITUCIONES POLITICAS FUNDAMENTALES}

\section{El Parlamento}

Siguiendo el esquema de la Constitución de 1933, la Carta actual intenta diseñar un sistema híbrido, ni presidencial ni parlamentario.

32 Se debe destacar que el PPC sumó a sus votos los de Acción Popular que sólo se presentaría a las elecciones de 1980 para ganarlas; de otro lado, por primera y única vez, un frente mayoritariamente trotskista se presenta como la tercera fuerza electoral.

${ }^{33}$ El Dr. Pareja esboża las tendencias de las Constituciones latinoamericanas recientes, donde hallamos la constitucionalización de los derechos sociales, el incremento de la protección de los derechos constitucionales, la tecnificación del aparato constitucional, la incorporación de principios de Derecho Internacional y el impulso a la integración, la importancia creciente de las cuestiones económicas y de los planes de desarrollo y planificación estatal, el incremento de la representación proporcional y de las minorías, la protección y defensa de los regímenes democráticos, la agudización del nacionalismo, la extensión del derecho de sufragio, la constitucionalización de los partidos políticos y la democratización e incremento de la autonomía de las instituciones locales. Véase PAREJA PAZ SOLDÁN, J.: Derecho constitucional..., op. cit., pág. 168 
Tomando como referencia el sistema de la Constitución francesa de la $\mathrm{V}$ República, pese a carecer de algunos elementos que a ésta le brinda una mayor estabilidad política, la Carta de 1979 introduce mejoras en el modelo mixto, como el derecho del Presidente para observar las leyes, la legislación delegada, el reconocimiento de la Cámara de Diputados como única Cámara política, etc.

La preferencia formal de iniciar el tratamiento constitucional de los Poderes del Estado por el Legislativo, deja entrever la ligera primacia teórica del Parlamento, sea por sus atribuciones legislativas o su intervención en los actos de gobierno que, en muchos casos, muestran cierta subordinación del Ejecutivo, por lo que se ha sostenido, nc sin críticas, que es el primer poder del Estado: «subyace aquí la tesis que por su origen, la pluralidad de su composición y la importancia de sus funciones dentro de un Estado de Derecho, la soberanía radica en el Parlamento" ${ }^{34}$.

Según establece el artículo 164 de la Carta, el Congreso es bicameral, dividido en una Cámara de Diputados y el Senado. En diversos artículos de los capitulos I y II del Título IV se aprecia un trato semejante para las Cámaras y sus miembros: renovación total y duración del mandato (arts. 166 y 167); presidentes de las Cámaras (arts. 168, 169 y 170); requisitos, prohibiciones, incompatibilidades, vacantes, inmunidades, etc. (arts. 171 a 179), y facultades legislativas idénticas (Capítulo II).

Junto a estas similitudes, existen otros aspectos que distinguen ambas Cámaras: a) sólo la Cámara de Diputados es la Cámara política, pudiendo interpelar, censurar y extender confianza a los ministros, así como ser disuelta por el Presidente de la República (arts. 225 a 229); b) en cuanto a la composición, el número de diputados triplica al de senadores y la edad mínima para el cargo varía (25 y 35 años); c) tienen diferentes roles en el antejuicio constitucional (arts. 183 y 184); d) el Presidente del Senado puede, circunstancialmente, ocupar la Presidencia de la República (art. 208); e) sólo el Senado tiene facultad para ratificar ascensos militares y altos cargos como magistrados supremos, embajadores, etc. (arts. 211, inc.15, 245 y 281); f) poseen diferentes formas de elección.

Fundamentalmente, el hecho de que sólo la Cámara de Diputados sea la Cámara política, es decir, que el Senado no puede poner en juego la responsabilidad del Gobierno, es el aspecto que acerca este modelo al que COLLIARD denomina como bicameralismo desigual ${ }^{35}$.

La opción por la bicameralidad coincide con la tradición constitucional peruana y, pese a que fue objeto de un amplio debate en la Constitu-

34 Rubio, M., y Bernales, E.: Constitución..., op. cit., pág. 311.

35 Colliard, Jean-Claude: Los regímenes parlamentarios contemporáneos. Barcelona, Edit. Blume, 1981, pág. 67. 
yente de 1931 —donde el APRA plantaba la unicameralidad—, esta vez sólo los partidos de izquierda propusieron tal opción ${ }^{36}$.

La elección de los senadores por regiones intenta dar justificación a la bicameralidad introduciendo un criterio de representación diverso. No obstante, la razón política de fondo, de talante conservador, es la de evitar una supuesta dictadura de Asamblea ${ }^{37}$.

La experiencia de los gobiernos posteriores a la Carta de 1979 ha demostrado el escaso sentido de esta bicameralismo, ya que en el campo legislativo son una copia y su conformación politica ha sido bastante homogénea auspiciada por la no utilización de la elección regional, fenómenos que han colaborado en la lentitud de la tarea legislativa y, a su vez, generado una reacción en favor del unicameralismo.

\section{A. Composicion de las Camaras}

La composición de la Cámara de Diputados la establece el articulo 167 de la Constitución: «La Cámara de Diputados es elegida por un período de cinco años. Se renueva íntegramente al expirar su mandato o en caso de ser disuelta conforme a la Constitución. El número de diputados es de 180. La ley fija su distribución tomando en cuenta, principalmente, la densidad electoral. Toda circunscripción tiene por lo menos un diputado".

La primera distorsión es introducida en el propio texto constitucional -Disposición Transitoria Quinta- donde se señala que la provincia de Lima tendrá 40 diputados, exhibiendo el lastre tradicional del centralismo capitalino ${ }^{38}$.

El derecho de sufragio ha sido ampliado a los analfabetos y a los mayores de dieciocho años, además del voto femenino. El voto, además de igual, libre y secreto, es obligatorio hasta los setenta años, medida que ha propiciado una alta participación electoral y, a su vez, un importante caudal

36 En contra de la bicameralidad encontramos, entre otros, a GARCiA BELAUUNDE, Domingo: Constitución y Política. Lima, Biblioteca Peruana de Derecho Constitucional, 1981, pág. 137; RuIz ELDREDGE, Alberto: La Constitución comentada. 1979. Lima, Editora Atlántida, S. A., 1980, pág. 260; y Rubıo, M.; Bernales, E.: Constitución..., op. cit., pág. 312. Además de la defensa que en 1931 efectuara BELAÚNDE, Victor Andrés: El debate constitucional. Discursos en la Asamblea 1931-32. Lima, Talleres Gráficos P. L. Villanueva, S. A., 1966; se puede acudir a PAREJA PAZ SOLDÁN, J.: Derecho Constitucional..., op. cit., pág. 340.

${ }^{37}$ En Latinoamerica países como Ecuador, Nicaragua y Panamá poseen un Parlamento unicameral sin que exista la dictadura de Asamblea.

38 Sobre el tema véase BASADRE, Jorge: Elecciones y centralismo en el Perú. Lima, Centro de Investigaciones de la Universidad del Pacífico, 1980. 
de votos nulos y en blanco ${ }^{39}$. Las elecciones se han realizado por listas de candidatos sobre las que existe el voto preferencial facultativo, con representación proporcional (art. 65) y distribuidos por el método D'Hont.

En el caso del Senado, el artículo 165 establece que «es elegido por las regiones, de conformidad con la ley". Complementando este precepto, la Disposición Transitoria Cuarta estableció que, mientras se constituyan todas las regiones, el Senado se elegirá en distrito nacional único. Lo cierto es que actualmente no existe ninguna región constituida, de suerte que las elecciones de 1980 y 1985 no se han realizado por regiones ${ }^{40}$.

El artículo 171 establece un mandato de cinco años igual que para los diputados, pero mientras que para éstos requiere una edad mínima de veinticinco años, para los senadores es de treinta y cinco. Su número es de 60, a los que debe agregarse los expresidentes constitucionales como senadores vitalicios. También se ha previsto que los candidatos a la Presidencia y Vicepresidencia de la República puedan serlo para diputados o senadores, medida criticada por propiciar la multiplicación de candidatos presidenciales.

Por último, entre las incompatibilidades que señala el artículo 173, entre el mandato legislativo y cualquier otra función pública, se exceptúa de modo expreso la de ser ministro de Estado. Ésta sería «una forma de acercarse al Gobierno de tipo parlamentario, aun cuando es el Presidente quien nombra los ministros sin intervención del Congreso» ${ }^{41}$.

\section{B. Organización y funcionamiento}

La organización de las Cámaras se guia por el principio de la autonomía. Si bien históricamente está dirigida a lograr su independencia principalmente frente al Poder Ejecutivo, no es menos cierto que hoy incluye también al Poder Judicial, los partidos políticos, grupos de presión e inclusive la opinión pública.

39 En las elecciones de 1985, de un total de aproximadamente ocho millones de electores, un 13 por 100 no votó y un 16 por 100 lo hizo en blanco o de forma nula. Fuente: Jurado Nacional de Elecciones, Resultados de las Elecciones Politicas Generales de 1985, vol. I, Lima, SAGSA, 1986, págs. 74 y 75.

40 Hasta hoy sólo ha sido aprobada la Ley de Bases de Regionalización, Ley 24650, de 19 de marzo de 1987.

${ }_{41}$ Esta prerrogativa ha sido utilizada con relativa frecuencia. Vease RuBı, M., y Bernales, E.: Constitución..., op. cit., pág. 320. 
La autonomía parlamentaria se plasma en determinados privilegios, sean éstos colectivos o individuales. Entre los primeros se halla la potestad de auto-reglamentarse, donde cada rama legislativa y el Congreso elaboran su propio reglamento, el que tiene rango de ley ${ }^{42}$; elige a sus representantes en la Comisión permanente y demás Comisiones y establece la organización y atribuciones de los grupos parlamentarios ${ }^{43}$. En lo económico también gozan de plena autonomia, sancionando su propio presupuesto. Por último, la organización administrativa y funcionarial también es potestad exclusiva de cada Cámara.

Los privilegios individuales, en adición a sus deberes, configuran el estatuto jurídico del parlamentario; la inviolabilidad, inmunidad, incompatibilidades, etc. (arts. 172 a 176). También se intenta proteger la independencia del parlamentario al establecer en el artículo 176 que "Los senadores y diputados representan a la Nación. No están sujetos al mandato imperativo".

La representación adquirida por los partidos quiere ser preservada cuando se establece que las vacantes serán cubiertas por los candidatos suplentes, según el orden en que aparecen en las listas. Pero la presión partidaria es, a su vez, mediatizada al otorgar el carácter irrenunciable al mandato del Parlamento (art. 178) ${ }^{44}$.

El Congreso tiene dos periodos de sesiones o legislaturas - como son denominadas en el artículo 168-, con fechas precisas señaladas en el texto constitucional; la primera se inicia el 27 de julio y culmina el 15 de diciembre, mientras que una segunda se abre el 1 de abril y termina el 31 de mayo; son en total seis meses y medio de funcionamiento anual. También están previstas legislaturas extraordinarias, con una duración máxima de quince días y en la que sólo se tratan los asuntos materia de la convocatoria, sea ésta hecha a iniciativa del Presidente de la República o los dos tercios de representantes de ambas Cámaras.

Mientras que la Carta del 33 permitía la auto-convocatoria del Congreso sólo en caso de omisión por parte del Presidente de la República, la vigente quiere lograr una mayor autonomía parlamentaria, encargando a los presidentes de cada Cámara la convocatoria de las legislaturas.

42 Debe de destacarse que recientemente se han modernizado los reglamentos internos que datan del siglo pasado, normas cuya especial importancia ha sido destacada por PAREJA PAZ Soldán, J.: Derecho Constitucional..., op. cit., página 348.

43 Notable omisión ha sido la de la elección de los miembros de la Directiva de cada Cámara.

44 Ya ha ocurrido que representantes elegidos gracias a los votos de determinado partido, hayan renunciado a su militancia pero no al cargo, lo que ha provocado críticas. Véase Rubıo, M., y Bernales, E.: Constitución..., op. cit. 
La experiencia de crisis políticas originadas en autorrecesos causados por el absentismo parlamentario ${ }^{45}$ propició la inclusión del artículo 170, cuya aplicación puede llevar a declarar la vacancia de los representantes ausentes y la imposibilidad de su postulación a cargo o función pública por diez años.

Respecto a las Comisiones parlamentarias destaca su excesivo número, tanto las dictaminadoras como las investigadoras o de encuesta. En el primer caso, el que sean varias Comisiones las que evalúen su dictamen ha hecho muy lento el proceso legislativo, tomando en cuenta, además, que sólo el pleno de la Cámara puede aprobar leyes; en el caso de las Comisiones de Encuesta, éstas han demostrado poca efectividad y en la mayoría de casos no alcanzan a emitir informe alguno ${ }^{46}$.

Las elecciones desde 1980 han permitido que el partido en el gobierno logre poseer, a su vez, mayoría en ambas Cámaras; de esta forma, la elaboración del «orden del día» en cada Cámara, gracias a la disciplina partidaria, se ha convertido en un instrumento de gran poder.

\section{Funciones del Parlamento}

Siguiendo una clasificación que es característica en un sistema de colaboración de poderes, las funciones del Parlamento las dividiremos en la legislativa, de control y financiera o presupuestaria ${ }^{47}$.

\section{a) Función legislativa}

Es idéntica en ambas Cámaras, por lo que es necesario su acuerdo para perfeccionar el acto. En cuanto al derecho de iniciativa lo poseen los diputados, senadores y el Presidente de la República de forma genérica, mientras que la Corte Suprema y el órgano de gobierno de la región en materias que le son propias (art. 190). Los ciudadanos no poseen este derecho individual ni colectivamente. Es destacable que los miembros del

45 Esta circunstancia tuvo su mayor crisis durante el gobierno de Bustamente y Rivero en 1945-48. Véase BUSTAMENTE y RIVERo, Luis: Tres años de lucha por la democracia en el Perú. Buenos Aires 1949.

${ }_{46}$ Las Comisiones se cuentan por decenas y su problemática en el Perú ha sido estudiada por Bernales, Enrique: El Parlamento por dentro. Lima, DESCO, 1984.

${ }^{47}$ Sobre esta materia existe un estupendo estudio de RuBIO, Marcial: «Los poderes políticos del Estado en la nueva Constitución», en la Revista de Derecho, Lima, Pontificia Universidad Católica, n. ${ }^{\circ} 35,1981$. 
Parlamento no tienen iniciativa en el gasto público (art. 199). El Presidente de la República debe promulgar las leyes dentro de los quince días, de lo contrario lo hace el Congreso; el veto suspensivo del Presidente se supera con la votación a favor de la mitad más uno del número legal de miembros de cada Cámara (art. 133).

\section{b) Función de control}

Siendo la Cámara política la de Diputados, es ésta la que dispone de los principales medios de control del Consejo de Ministros como la interpelación (225), el voto de censura y el voto de confianza ${ }^{48}$-artículos 225 y 226-, este último sólo a iniciativa ministerial. Las Comisiones de Encuesta son posibles en ambas Cámaras. El Senado posee cierto control sobre el nombramiento de autoridades y altos cargos (arts. 211, incs. 15, 245,281 ). El juicio político al Presidente de la República, ministros, parlamentarios, magistrados supremos, etc., por infracción de la Constitución o delito cometido durante el ejercicio de sus funciones, brinda a la Cámara de Diputados la facultad de acusar ante el Senado, el que decide si hay lugar a la formación de causa, suspendiendo al acusado en el ejercicio de sus funciones y sometiéndolo al Poder Judicial (arts. 183 y 184).

\section{c) Función financiera}

Corresponde al Congreso o reunión de ambas Cámaras aprobar el Presupuesto y la Cuenta General, así como autorizar empréstitos (art. 186, incs. 4 y 5). La Constitución ha destacado la importancia del procedimiento de aprobación del presupuesto al reservar todo el capítulo IV del Título IV para su regulación. Entre dichos preceptos destaca la presentación del presupuesto por el Presidente de la República en el mes de agosto del año anterior al de su vigencia, su estudio y dictamen es efectuado por una Comisión mixta especial compuesta de ocho miembros de cada Cámara; la promulgación del proyecto de presupuesto del Poder Ejecutivo en caso de no aprobarse las modificantes de 15 de diciembre ${ }^{49}$.

48 Un análisis exhaustivo del control del Parlamento puede consultarse en Melo-VEgA C., Jorge: "Control parlamentario", en la obra colectiva La Constitución Peruana de 1979 y sus problemas de aplicación. Lima, Editorial Cuzco, 1987.

49 En más de una oportunidad se ha salvado el no trasponer la fecha límite deteniendo las manecillas del reloj a la medianoche. 


\section{El Presidente de la República}

Siguiendo la clasificación efectuada por DUVERGER ${ }^{50}$, el régimen peruano que construido a partir de la Constitución de 1979 seria semi-presidencial, considerando que el Presidente de la República es elegido por sufragio universal directo y posee poderes propios que exceden a los del presidente cuyo origen y Gabinete provienen del Parlamento y que, por otro lado, debe soportar el control parlamentario y las facultades de interpelación y censura de ministros reconocidas a la Cámara de Diputados.

La figura presidencial tiene un perfil histórico particular en Latinoamérica $y$, en especial, en el Perú. Como hemos visto, la organización político-constitucional fue formalmente liberal, rigiendo una teórica separación de poderes; en la práctica, existió un gobierno centralizado y una cabeza visible con carácter paternalista: el Presidente de la República ${ }^{51}$.

Hacia 1931, VILLARÁN destacaba que «la institución del Presidente con facultades propias y extensas de gobernante efectivo, está sustentada en el Perú y en la América por toda una fortísima tradición y por hábitos populares incoercibles. Responde a un estado social y económico que impone sus leyes inflexibles a la evolución política. No podemos imaginar la abolición del régimen presidencial sino como resultado de un cambio de cosas profundo precedido tal vez de una revolución" ${ }^{52}$. La preponderancia presidencial, según PAREJA PAZ SOLDÁN, tiene explicación en dos elementos fundamentales. Por un lado, la tendencia al paternalismo político, expresado en la personalización del poder en un caudillo y, en segundo término, el hecho de que en las elecciones primen las condiciones personales sobre las ideologias del partido o su programa de gobierno ${ }^{53}$. Finalmente, BERNALES, luego de destacar la personalidad carismática -en términos weberianos - de la figura presidencial peruana, completa la explicación del fenómeno al poner de relieve la fragilidad de las clases sociales, cuya escasa diferenciación y afirmación las hace proclives al arrastre de tipo populista ${ }^{54}$.

En síntesis, la Carta de 1979 ha reforzado de manera notable al Presidente de la República y destacado el rol preponderante del Poder Ejecutivo en el sistema mixto adoptado.

50 DUVERger, Maurice: Instituciones Politicas y Derecho Constitucional. Barcelona, Ariel, 1970, pág. 294.

${ }_{51}$ El carácter paternalista de esta figura tiene su antecedente histórico, según Kaplan, en la monarquía centralizada de la época colonial. Véase KAPLAN, Marcos: Formación del Estado Nacional en América Latina. Santiago de Chile, Editorial Universitaria, 1969, págs. 69 y ss.

52 : Villaran, M. V.: Anteproyecto..., op. cit., pág. 41.

53 Pareja Paz Soldán, J.: Derecho constitucional..., op. cit., pág. 252.

54 Rubio, M., y Bernales, E.: Constitución..., op. cit., pág. 351. 


\section{A. ELECCION DEL PRESIDENTE DE LA REPÚBLICA}

El Presidente de la República es elegido por sufragio directo, condición considerada característica del sistema presidencial. Junto a él se eligen a un primer y segundo vicepresidentes. Para postular a dichos cargos se requiere ser peruano de nacimiento y gozar de derecho de sufragio, estableciendo una edad minima de treinta y cinco años, la misma que para senador. Ello ha permitido acceder a la Presidencia en 1985 al candidato del Partido Aprista, Alan García, con la edad mínima requerida.

El mandato del Presidente es igual al que corresponde a los senadores y diputados, es decir, cinco años. Además de coincidir los mandatos, las elecciones presidenciales y parlamentarias se realizan también conjuntamente. Estas medidas tienden a lograr la estabilidad del régimen dado que, siendo el Presidente el verdadero conductor del gobierno, debe recurrir a la colaboración de sus ministros, los que pueden ser interpelados y censurados por el Parlamento. Por esta razón, las elecciones conjuntas propician que la mayoría parlamentaria sea favorable al Presidente, situación que de hecho se ha producido en las dos elecciones realizadas desde 1980. Sin la colaboración entre el Presidente de la República y el Parlamento el sistema no funciona y se generarían graves problemas políticos, como los que señala DUVERGER para el sistema semipresidencial de Francia $^{55}$.

En cuanto al sistema de elección presidencial encontramos importantes modificaciones que han alterado la práctica político-electoral del país. El artículo 203 dispon ₹ lo siguiente:

«El Presidente de la República es elegido por sufragio directo y por más de la mitad de los votos válidamente omitidos. Si ninguno de los candidatos obtiene la mayoría absoluta, se produce una segunda elección dentro de los treinta días siguientes entre los candidatos que han obtenido las dos más altas mayorias relativas. Junto con el Presidente de la República son elegidos, de la misma manera y por igual término, un primer y un segundo vicepresidentes".

El sufragio universal y el elevado porcentaje de votos -lo común ha sido entre 30 y 36 por 100 - tienden a dotar de prestigio y ancha base social al Presidente de la República como «Jefe del Estado» que «personifica la Nación» (art. 201). Otra consecuencia será el condicionamiento

s5 Duverger, M.: Instituciones..., op. cit., pág. 300. 
para una segunda vuelta electoral. El sistema de elección a dos vueltas tomado de la Francia de la V República - con la diferencia que en el Perú no se aplica a la elección de parlamentarios-, constituye un elemento innovador y cuestionado que, como veremos, ha causado importantes problemas políticos.

En el caso francés, DUVERGER ${ }^{56}$ ensayó una interpretación política de su justificación: a) la lucha contra el pluripartidismo y la orientación hacia el bipartidismo, y b) forzar alianzas electorales que propician la bipolarización izquierda-derecha. Esta bipolarización, en caso de una segunda vuelta electoral, favorece el triunfo conservador, explotando el anticomunismo francés $y$, en el caso específico del Perú, el anticomunismo y el antiaprismo ${ }^{57}$. Por esta razón, BERNALES destacó que la segunda vuelta tiene un claro propósito antidemocrático y persigue distorsionar la voluntad popular forzándola a opciones bipolares antagónicas que no corresponden con el espectro pluripartidario o ideológico de la gran mayoría de los pueblos ${ }^{58}$.

Los problemas de este sistema no se verificaron para las primeras elecciones realizadas en 1980, merced a que en la Disposición Transitoria Tercera de la Carta se estableció que para dichos comicios el sistema fuese a una sola vuelta, proclamándose Presidente de la República al candidato que reúna el 36 por 100 de los votos válidos; de no lograr nadie reunir dicho porcentaje, el Congreso lo elegiría de entre los más votados. Este último procedimiento no fue utilizado, pues Fernando Belaúnde logró el 45 por 100 de los votos válidos en 1980 .

La adopción de la mayoría absoluta propicia la utilización de la segunda vuelta e introdujo un elemento interpretativo sobre los «votos válidamente emitidos». El artículo 60 de la Ley 23903 consideró como válidamente emitidos los votos blancos y nulos para las elecciones de 1985, donde entra en vigencia el sistema de doble vuelta. Se torna mucho más difícil reunir tal número de votos en una primera vuelta y se induce a una vuelta electoral con los ingredientes antidemocráticos que anotamos.

Esta interpretación del alcance del artículo 203 efectuada en la Ley 23903 fue recurrida al Tribunal de Garantias Constitucionales a fin de que declare su inconstitucionalidad ${ }^{59}$.

56 Duverger, M.: Instituciones..., op. cit., pág. 302.

57 La propuesta de este sistema provino del conservador Partido Popular Cristiano y los riesgos de la utilización del antiaprismo fue puesto de relieve por ChiRinos Soto, Enrique: La Constitución al alcance de todos. Lima, Editorial Andina, 1969, págs. 212 y ss.

${ }_{58}$ Rubio, M., y Bernales, E.: Constitución..., op. cit., pág. 359.

59 La demanda de inconstitucionalidad fue firmada por 61 diputados de distintos grupos políticos de oposición en dicho momento, siendo defendida por el Dr. Javier Valle Riestra. Véase VALLe RIESTRA, Javier: El Tribunal de Garantias Constitucionales. El caso de los votos nulos y blancos. Lima, Labrusa, 1986. 
Ante la inminencia del proceso electoral, el pronunciamiento del Tribunal era fundamental y no se produjo al no reunir los seis votos necesarios para declarar la inexequibilidad de la Ley. Las elecciones de 1985 se guiaron por el criterio anterior, evitando que el candidato del Partido Aprista obtuviera la victoria en la primera vuelta. Sólo la renuncia de Barrantes Lingán, candidato de Izquierda Unida y segundo más votado, evitó la segunda vuelta.

\section{B. FINALIZACION DEL MANDATO PRESIDENCIAL}

Tal como dispone el artículo 206 de la Constitución la Presidencia de la República queda vacante, antes de finalizado el mandato de cinco años, por muerte, incapacidad moral o permanente incapacidad física, dimisión, alejamiento del territorio nacional y destitución.

Salvo en el supuesto de muerte del Presidente de la República, comprobamos el rol fundamental que cumple el Parlamento. En el supuesto de incapacidad física o moral, la declaración le corresponde hacerla al Congreso; si el Presidente sale al exterior sin permiso del Congreso o retorna vencido el plazo cesa en el cargo. Debe destacarse que en caso de falta temporal del Presidente asumen el cargo el primer vicepresidente, en su defecto el segundo, y en defecto de éste el Presidente del Senado, quien de inmediato convoca a elecciones (art. 208).

El supuesto de la destitución se halla íntimamente ligado a la irresponsabilidad política, civil y penal del Presidente de la República, consignada en el artículo 210, que señala a título de excepción los casos en que puede ser acusado durante su período: traición, impedir las elecciones o el funcionamiento del Jurado Nacional de Elecciones o el Tribunal de Garantías Constitucionales, asi como el disolver el Congreso, salvo la Cámara de Diputados en el caso que contempla la propia Constitución. La Cámara de Diputados se encarga de acusarlo ante el Senado, el que decide si hay lugar a la formación de causa, pasando a juicio (arts. 183 y 184) ${ }^{60}$.

La irresponsabilidad política también se expresa en la nulidad de los actos del Presidente de la República que carezcan de refrendación ministerial (art. 213), así como por la responsabilidad individual de los ministros de los actos presidenciales que refrendan y la responsabilidad solidaria de todos los ministros por actos delictuosos o infractorios de la Constitución en que incurra el Presidente de la República (art. 221).

6o Véase Valle Riestra, Javier: La responsabilidad constitucional del Jefe de Estado. Lima, Benítez Rivas-Montejo, 1987. 


\section{Atribuciones del Presidente de la República}

\section{a) Relacionadas con el Gobierno}

La posición del Presidente de la República respecto del Gobierno se manifiesta en el último inciso del artículo 211, que aludiendo a las facultades no enumeradas expresamente en los 25 incisos precedentes, señala que le compete «ejercer las demás funciones de gobierno y administración que la Constitución y las leyes le encomiendan». Señalamos a continuación las más importantes.

Designación del primer ministro.-Conforme al artículo 216, el Presidente de la República nombra y remueve al presidente del Consejo de Ministros. Para ello goza de plena autonomía del Parlamento, aunque ha sido frecuente que algún representante, sin perder el mandato legislativo, haya sido designado primer ministro.

Designación del Gobierno.-Conectado con lo antes expuesto, el segundo párrafo del citado artículo 216 establece que el Presidente nombra a los ministros o los remueve, a propuesta y con acuerdo del primer ministro, respectivamente. Cuando se forma un nuevo Gabinete ministerial, el presidente del Consejo expone y debate ante el Congreso su programa, sin que pueda haber voto sobre el mismo. Es decir, el Congreso no inviste al Gobierno.

Presidencia del Consejo de Ministros.-De acuerdo con el artículo 215 «corresponde al Presidente de la República presidir el Consejo de Ministros cuando lo convoca o asiste a sus reuniones». La práctica política es que el Consejo de Ministros siempre se reúna a instancias del Presidente, ergo, éste siempre lo preside. Sobre ello resulta claro el inciso 3 del artículo 211 , en tanto señala como una de sus atribuciones el «dirigir la política general del Gobierno».

Administración de la Hacienda Pública.—Los incisos 20 a 23 del artículo 211 facultan al Presidente para administrar la Hacienda Pública, aprobar los planes nacionales de desarrollo y regular las tarifas arancelarias.

Dictado de decretos y resoluciones.-El Presidente de la República, según el artículo 210, inciso 11, ejerce la potestad de reglamentar las leyes dictando al efecto decretos y resoluciones que requieren del refrendo ministerial. Debe destacarse que en virtud del inciso 29 del mismo artículo, se han dictado medidas extraordinarias en materia económica y financiera, 
cuya naturaleza es aún materia de debate doctrinal, pero que en los hechos ha derogado $y$ modificado leyes ${ }^{61}$.

Nombramientos de altos cargos.-El Presidente nombra a tres miembros del Tribunal de Garantias Constitucionales, a los magistrados y fiscales supremos, militares de alta graduación, así como al presidente del Banco Central de Reserva, todos ellos deben ser ratificados por el Senado.

En el caso del controlador general de la República, el Presidente hace la propuesta y el Senado lo designa.

Jefatura de las Fuerza Armadas.-En virtud del artículo 273, el Presidente de la República es el jefe supremo de las Fuerzas Armadas y Policiales, dirigiendo el Sistema de Defensa Nacional. Declara la guerra y firma la paz, con la autorización del Congreso (artículo 211, inc. 19).

Dirección de la política exterior.-Dirige las relaciones internacionales y la política exterior, nombra embajadores (ratificados por el Senado) y recibe la acreditación de los agentes diplomáticos extranjeros (arts. 211, incisos 14, 15 y 16).

Negociación y ratificación de tratados.- - Los tratados internacionales son negociados y suscritos por el Presidente de la República y, luego de su aprobación por el Congreso, también son ratificados por él. En virtud del artículo 104, está en capacidad de celebrar o ratificar convenios internacionales sobre materias de su exclusiva competencia, sin el requisito previo de la aprobación del Congreso.

\section{b) Relacionadas con el Parlamento}

Derecho de iniciativa en las leyes.-De acuerdo con el artículo 211, inciso 8, puede presentar proyectos de ley ante las Cámaras, los que tendrán preferencia si tiene el carácter de urgente. La práctica legislativa revela que el Poder Ejecutivo ha sido el principal legislador hasta hoy, en virtud de este derecho, así como por la delegación de facultades que pasamos a ver ${ }^{62}$.

61 Al amparo de esta atribución se han dictado varios cientos de decretos que han modificado incluso la Ley de Presupuesto. Su número, forma jurídica, así como la falta de precisión en la redacción constitucional, hacen dudosa su asimilación a los decretos de necesidad y urgencia. Sobre ello véase EguIGuREN P., Francisco: "Los decretos de necesidad y urgencia", Revista de Derecho, n. ${ }^{\circ} 40$, Facultad de Derecho Pontificia Universidad Católica del Perú, diciembre de 1986.

${ }_{62}$ Véase Bernales, E.: El Parlamento..., op. cit., págs. 43 y ss., y Eguiguren, F.: «Funciones legislativas del Poder Ejecutivo», en La Constitución peruana de 1979 y sus problemas..., op. cit., pp. 395 y ss. 
Dictado de Decretos Legislativos.-El Presidente de la República, en virtud del artículo 211, inciso 10, puede dicta Decretos Legislativos con fuerza de Ley, previa delegación de facultades del Congreso y con cargo a darle cuenta. La ley autoritativa fija la materia y el término de la delegación (art. 188).

La observación de las leyes.-Conforme al artículo 193, el Presidente puede conservar un proyecto aprobado por el Congreso. En la nueva deliberación es necesario reunir los votos de más de la mitad del número legal de miembros de cada Cámara para que el Congreso promulgue la Ley observada. De no existir observación, este mismo precepto encarga al Presidente la promulgación de las leyes.

Convocatoria de legislaturas extraordinarias.-Le compete también al Presidente - tal como expresa el artículo 168- la convocatoria de legislaturas extraordinarias del Congreso, debiendo fijar el asunto a tratar, así como la fecha de inicio y clausura de la legislatura, la que en ningún caso puede exceder los quince días.

Disolución de la Cámara de Diputados.-Si la Cámara política ha censurado o negado confianza a tres Consejos de Ministros, el Presidente se halla facultado por el artículo 227 para disolver dicha Cámara ${ }^{63}$. El decreto de disolución debe ser motivado e incluir la convocatoria de nuevas elecciones de diputados dentro de los treinta dias siguientes. De no cumplir con este requisito, la Cámara de Diputados recobra sus facultades y cesa al Consejo de Ministros los que, según el artículo 228, no pueden ser elegidos nuevamente hasta finalizado el mandato presidencial. Esta prerrogativa sólo puede ser ejercitada en una oportunidad durante el mandato presidencial. Por otro lado, el Presidente está impedido de disolver la Cámara durante el estado de sitio o de emergencia, asi como en el último año de su mandato. En este último caso, el voto de censura debe contar con el voto conforme de los dos tercios del número legal de miembros.

Dirigir mensajes al Congreso.-El artículo 211, inciso 7 , obliga al Presidente a dirigir un mensaje al Congreso, en forma personal y por escrito, al instalarse cada primera Legislatura Ordinaria y al concluir su mandato ${ }^{64}$. Fuera de estos casos, el Presidente puede dirigir estos mensajes en cualquier época por propia iniciativa. Siempre que se dirija un mensaje al Congreso debe contar con la aprobación del Consejo de Ministros, sin que en ningún caso origine el voto del Congreso.

63 Hasta la fecha no ha sido aprobada ninguna moción de censura, individual o colectiva, por lo que no ha sido preciso utilizar esta prerrogativa presidencial.

${ }_{64}$ Tiene semejanza con la exposición del primer ministro en vista que el mismo precepto señala que los discursos obligatorios «contienen la exposición detallada de la situación de la República y las mejoras y reformas que el Presidente juzga necesarias y convenientes para su consideración por el Congreso". 
c) Relacionadas con la Magistratura

El Presidente de la República mantiene una doble posición en esta materia pues es el encargado de "cumplir y hacer cumplir las sentencias y resoluciones de los tribunales y juzgados", mientras que, por otro lado, puede "requerirlos para la pronta administración de justicia» (art. 211, inciso 12). También posee las siguientes atribuciones:

Nombramiento de magistrados.-El artículo 245 encarga al Presidente el nombramiento de los magistrados, a propuesta del Consejo Nacional de la Magistratura. En el caso de los magistrados de la Corte Suprema es necesaria la ratificación del Senado. Según el artículo 296, también participa en la designación de tres de los nueve miembros que componen el Tribunal de Garantias Constitucionales.

Derecho de gracia.-Es potestad del Presidente de la República, en su papel de juez supremo, conceder indultos y conmutar penas.

Interposición de la acción de inconstitucionalidad.-De conformidad con el artículo 299, el Presidente de la República tiene facultad para interponer esta acción ante el Tribunal de Garantías Constitucionales. Es una prerrogativa importante, considerando que en el caso de los diputados y senadores, es preciso contar con el apoyo de, al menos, la tercera parte de ellos.

\section{El Consejo de Ministros}

El Consejo de Ministros viene regulado en el Capítulo VI del Título IV de la Constitución y, de acuerdo con el artículo 212 de la misma, tiene a su cargo la dirección y gestión de los servicios públicos. El Consejo, y cada ministro de forma individual, son responsables ante la Cámara de Diputados en las condiciones y de acuerdo a los procedimientos previstos en los artículos 225 y 226. El Consejo de Ministros aparece como un órgano independiente, aunque de hecho se produce una clara dependencia respecto del Presidente de la República.

\section{A. COMPOSICION}

El Consejo de Ministros, de acuerdo con el artículo 215, posee su propio presidente quien tiene a su cargo una cartera ministerial al igual que los demás ministros. Se presenta más como un primus inter pares que como un primer ministro. Las principales funciones que la Constitución le 
asigna son asumidas de hecho por el Presidente de la República. Aunque la Constitución no lo prevé, existen algunos altos funcionarios a los que se les reconoce el rango de ministro, participando con frecuencia en las sesiones del Consejo. Es común también hallar a funcionarios que tienen bajo su responsabilidad parcelas de una cartera ministerial a los que se denomina viceministros.

\section{B. NOMBRAMIENTO}

El presidente del Consejo de Ministros es nombrado y removido a iniciativa del Presidente de la República (art. 216). El Parlamento no interviene, ni a título consultivo, en la designación. Pese a que formalmente la Constitución dispone que los demás ministros los nombra y remueve el Presidente de la República a propuesta y con acuerdo, respectivamente, del presidente del Consejo, la práctica política muestra una amplia iniciativa presidencial.

Constituido el Gobierno, el presidente del Consejo concurre al Congreso en compañía de todos sus ministros para exponer y debatir su programa (art. 224). No se trata de una sesión de investidura del Gobierno, pues la exposición no da lugar al voto del Congreso. Únicamente por iniciativa ministerial se otorga el voto de confianza que, de no aprobarse, origina la dimisión ante el Presidente de la República.

El artículo 219 regula las incompatibilidades de los ministros, no pudiendo ejercer otra función pública, excepto la legislativa, como reseñamos anteriormente. Los ministros tampoco pueden ejercer ninguna actividad lucrativa ni intervenir, directa o indirectamente, en la dirección o gestión de empresas ni asociaciones privadas. Con estas medidas se pretende salvaguardar la libertad de actuación de los ministros en relación con otros entes públicos o privados.

\section{ATRIBUCIONES}

El presidente del Consejo de Ministros posee, conforme a la Constitución, tres atribuciones básicas: presidir las sesiones en ausencia del Presidente de la República, proponer a lós demás ministros y dirigirse a las Cámaras en representación del Consejo.

Las atribuciones del Consejo de Ministros se encuentran reguladas en el artículo 218 que las enumera brevemente: 1) aprobar los proyectos de ley que el presidente somete a las Cámaras; 2) aprobar los Decretos Legislativos que dicta el Presidente de la República; 3) deliberar sobre 
todos los asuntos de interés público, y 4) las demás que le otorga la Constitución.

\section{LA DESCENTRALIZACIÓN POLITICA}

El artículo 79 de la Constitución señala que el Perú tiene un gobierno unitario, representativo y descentralizado. El tema de la descentralización es tratado en el Capítulo XII del Título IV de la Constitución, regulando los gobiernos locales y regionales, cuyas características más importantes pasamos a detallar.

\section{A. LOS GoBIERNOS LOCALES}

Los órganos del gobierno local son las Municipalidades, distribuidas administrativamente en Consejos Municipales provinciales y de distrito básicamente (art. 252). El Consejo Municipal cuenta con un alcalde y un número de regidores establecido en función de la población. Son elegidos por sufragio directo, pudiendo elegir y ser elegidos los extranjeros cumpliendo algunos requisitos mínimos.

La autonomía administrativa y económica que le recoroce la Constitución se pretende asegurar otorgándoles competencias como la de acordar su organización interna y votar su presupuesto, administrar sus bienes y rentas, reglamentar y administrar los servicios públicos locales, crear, modificar o suprimir contribuciones, arbitrios y derechos, etc. (art. 254). Para el caso concreto de los Consejos Municipales provinciales, la Constitución les encarga además la zonificación y el urbanismo, educación primaria en forma de cooperación, cultura, recreación y deportes, turismo y cementerios (art. 255). La autonomía económica se sustenta en las rentas provenientes de impuestos, licencias, patentes, arbitrios, etc. Sobre diversas actividades señaladas en el artículo 257 de la Constitución.

Con la Constitución de 1979 se ha retornado a la elección de los gobiernos locales, cuya actuación se ha incrementado notablemente. Las elecciones municipales se efectúan cada tres años, constituyendo un dato importante sobre el desgaste que ha sufrido el partido en el gobierno.

\section{B. LOS GobieRnOS REGIONALES}

La descentralización regional constituye una innovación en la estructura politica del Perú. La organización territorial tradicional responde 
al esquema francés de departamentos e intendencias, estas últimas llamadas provincias. La Constitución ordena que la descentralización se efectúe conforme a un plan que ha sido aprobado mediante la Ley 23878 , de 20 de junio de 1984, que divide al Perú en no más de 12 regiones. Su organización básica se halla regulada en la Ley de Bases de la Regionalización número 24650 , de 19 de marzo de 1987. La conformación efectiva de las regiones aún está en proceso.

Según el artículo 261 las regiones poseen autonomía económica y administrativa. Para tal efecto tienen competencia en materias como salubridad, vivienda, obras públicas, vialidad, agricultura, mineria, industria, comercio, energía, trabajo, seguridad social y educación. Su autonomía económica se pretende asegurar mediante cuotas del Fondo de Compensación Regional y otras sumas consignadas en el Presupuesto del Sector público, así como recursos nacionales que se les transfieren para la atención de los servicios públicos descentralizados, impuestos cedidos y otros creados por las mismas regiones, etc. (art. 262).

Los órganos de gobierno regional están regulados en los artículos 264 a 268 de la Constitución y son la Asamblea Regional, el Consejo Regional y la Presidencia del Consejo. La Asamblea Regional está compuesta por miembros elegidos por sufragio directo, por los alcaldes provinciales y por delegados de las instituciones representativas de las actividades económico-sociales y culturales de la región. La proporción y el número de miembros se determina en la ley de creación de cada región, aunque el artículo 264 señala que los miembros directamente elegidos no pueden ser más del 40 por 100 del total.

Dentro de las atribuciones que el artículo 265 otorga a la Asamblea destaca la de elegir de su seno a su presidente, el que a su vez presidirá el Consejo Regional. Luego, a propuesta del presidente, la Asamblea elige a los demás miembros del Consejo. También tiene competencia para ejercer las competencias legislativas y administrativas que expresamente le delegan los Poderes Legislativo y Ejecutivo, dictar las normas de su organización, aprobar su presupuesto y el Plan Regional de Desarrollo.

Sobre la competencia legislativa posee el derecho de iniciativa en las leyes, en las materias que son de su competencia. Las delegaciones de competencias acordadas por el Parlamento suponen siempre la subordinación a la legislación nacional, por lo que el artículo 266 establece que «no pueden ser objeto de delegación las materias que alteran el carácter unitario de la República o el ordenamiento jurídico del Estado o que pueden ser opuestas al interés nacional o al de otras regiones". Las normas aprobadas por la Asamblea Regional son promulgadas por el Poder Ejecutivo, el cual tiene facultad de vetarlas.

El presidente y el Consejo Regional constituyen el órgano ejecutivo de la región. Sus principales funciones son las de ejecutar y reglamentar las normas emanadas de la Asamblea Regional, elaborar el proyecto de 
Plan Regional de Desarrollo y organizar y administrar los servicios públicos descentralizados, de acuerdo y en coordinación con el Poder Ejecutivo. Finalmente, constituye la última instancia resolutiva de los asuntos administrativos de los Consejos Municipales.

\section{EL TRIBUNAL DE GARANTIAAS CONSTITUCIONALES}

La Constitución prevé el control constitucional difundido, por parte del Poder Judicial, mediante el artículo 236, donde se lee: «En caso de incompatibilidad entre una norma constitucional y una legal ordinaria, el juez prefiere la primera». También con carácter casuístico, el juez puede inaplicar una norma incompatible con la Constitución durante el procedimiento de las acciones de garantía como son el habeas corpus y el amparo, contemplados en el artículo 295 de la Constitución ${ }^{65}$. La infracción de la Constitución o la ley proveniente de reglamentos y normas administrativas de carácter general habilita al afectado a recurrir al Poder Judicial mediante la acción popular.

La novedad que incorpora el texto constitucional es el control concentrado de la constitucionalidad a través del Tribunal de Garantías Constitucionales, nombre tomado de la Constitución española de la Segunda República, cuyos principales aspectos reseñamos a continuación.

\section{A. COMPOSICION}

Según el artículo 296, el Tribunal de Garantías Constitucionales es el órgano de control de la Constitución y se compone de nueve miembros: tres designados por el Congreso, tres por el Poder Ejecutivo y tres por la Corte Suprema. Los procedimientos de elección no establecen ninguna modificación al ordinario, de modo que, conforme al artículo 10 de la Ley Orgánica del Tribunal ${ }^{66}$, el presidente designa a los magistrados con el voto aprobatorio del Consejo de Ministros, el Congreso mediante Resolución Legislativa y la Corte Suprema en acuerdo de Sala Plena. El período de

${ }_{65}$ Sobre estas acciones puede consultarse a BorEa OdRIA, A.: El amparo y el habeas corpus en el Perú de hoy. Lima, Biblioteca Peruana de Derecho Constitucional, 1985.

${ }_{66}$ El texto completo de la ley se halla en la obra de PAREJA PAz SOLDÁn, J.: Derecho Constitucional, op. cit., apéndice II. 
mandato es de seis años, renovándose por tercios cada dos años, pudiendo ser reelegidos sus miembros. Su estatuto jurídico es similar al de los parlamentarios: inviolabilidad, inmunidad, no sujeción al mandato imperativo, etcétera (art. 297), consignándose en el primer artículo de su Ley Orgánica que sólo están sometidos a la Constitución y a dicha ley.

Los requisitos para ser magistrado del Tribunal son los mismos que para ser vocal de la Corte Suprema, por lo que son elegidos entre magistrados, catedráticos de alguna materia jurídica o abogados con más de veinte años de ejercicio, añadiendo que deben tener «probada ejecutoria democrática y en defensa de los derechos humanos». El ejercicio del mandato es incompatible con el de parlamentario, con el ejercicio de la profesión y demás funciones y cargos, públicos o privados, señalados en el artículo 14 de la Ley Orgánica. Los magistrados eligen a su propio presidente para un mandato de dos años con la posibilidad de una sola reelección.

\section{B. Competencias}

De acuerdo con el artículo 298 de la Constitución, el Tribunal de Garantías Constitucionales tiene las siguientes competencias: a) declarar, a toda petición de parte, la inconstitucionalidad parcial o total de las leyes, decretos legislativos, normas regionales de carácter general y ordenanzas municipales que contravengan la Constitución por la forma o por el fondo ${ }^{67}$, y b) conocer en tasación las resoluciones denegatorias de la acción del habeas corpus y la acción de amparo, agotada la vía judicial.

El derecho de interponer la acción de inconstitucionalidad ante el Tribunal está restringido para el Presidente de la República, la Corte Suprema, el fiscal de la Nación, 60 diputados o 20 senadores y 50.000 ciudadanos (art. 299).

La sentencia que declara la inconstitucionalidad de una norma no tiene efecto retroactivo; si se trata de una norma emanada del Poder Legislativo, la sentencia debe ser comunicada al Presidente del Congreso y, por el mérito del fallo, el Parlamento debe derogar dicha norma. Si dentro de los cuarenta y cinco días siguientes, el Congreso no cumple con la derogación, ésta se presume y el Tribunal ordena la publicación de la sentencia. Las sentencias que declaran la inconstitucionalidad de normas que

67 Véase SousA, Martha, y Danos, Jorge: «El control jurisdiccional de la constitucionalidad de las normas jurídicas de carácter general», en La Constitución peruana de 1979 y sus problemas..., op. cit. 
no provengan del Poder Legislativo son publicadas por orden del Tribunal y surten efecto desde el día siguiente de su publicación (art. 302).

Agotada la' vía judicial, las resoluciones denegatorias de las acciones de amparo y habeas corpus pueden llegar hasta el Tribunal mediante el recurso extraordinario de casación. Pueden interponerlo las partes o el ministerio público. Es el único supuesto en que pueden acceder los particulares. El fallo de casación constituye la última instancia jurisdiccional interna, pero quien se considere lesionado en los derechos que la Constitución le reconoce, en virtud del artículo 305 puede recurrir a los tribunales internacionales constituidos según los tratados de los que es parte el Perú.

El papel que ha desarrollado el Tribunal de Garantías Constitucionales ha sido bastante discreto, entre otras razones, por el escaso número de sentencias emitidas. La acción de inconstitucionalidad más relevante, sobre la inclusión de los votos nulos y en blanco como válidos por una ley que ya comentamos, no pudo ser resuelta por no existir acuerdo entre sus miembros. Su función como Tribunal de Casación ha sido, igualmente, poco relevante hasta hoy ${ }^{68}$.

\section{SITUACIÓN ACTUAL DEL RÉGIMEN PERUANO}

El primer elemento a tomarse en cuenta para comprender la realidad del régimen político peruano es el retorno a la democracia y al Estado de Derecho. Como hemos apreciado en las apretadas líneas sobre la evolución constitucional peruana, los momentos de democracia han sido esporádicos y es dificil encontrar una sucesión presidencial de carácter civil. La dicotomía entre la Constitución «formal» y la «real» es parte de esta realidad. Cuando se convocan elecciones para la Asamblea Constituyente de 1978, los peruanos hacen uso de su derecho al sufragio luego de prácticamente quince años.

El resultado de las elecciones para la Asamblea Constituyente demuestra un importante cambio en la composición política partidaria desde las elecciones generales de 1963. El aspecto más relevante es el importantísimo crecimiento de los diversos grupos de izquierda que, aunque se presentan de forma aislada, obtienen más del 30 por 100 de los votos, comparado con algo más del 1 por 100 de las últimas elecciones. Este explosivo

68 Véase al respecto García Pelayo, M.; Rubio Correa, M.; Garcia BelaúnDE, D., y otros: El Tribunal de Garantias Constitucionales en debate. Lima, Fundación Friederich Naumann, 1987. 
crecimiento tiene explicación diversa. Por un lado, se trata de nuevos grupos formados o impulsados durante el gobierno progresista del general Velasco. También significó una opción electoral para un importante sector que, por principio, desconfiaba de la democracia formal y en elecciones previas fue vetado como ha sido el caso del Partido Comunista de orientación soviética. Finalmente, debe tomarse en cuenta que el derecho de sufragio fue extendido a los analfabetos y mayores de dieciocho años, sector con importante influencia de izquierda.

La Asamblea Constituyente estuvo dividida básicamente en un sector socialdemócrata, el Partido Aprista, con el 35,27 por 100; un sector conservador, el Partido Popular Cristiano, con el 23,64 por 100, y grupos de izquierda de diversa tendencia: Frente Obrero Campesino Estudiantil y Popular $(12,31 \%)$, Partido Socialista Revolucionario $(6,6 \%)$, Partido Comunista Peruano $(5,90 \%)$, Unidad Democrática Popular $(4,76 \%)$, que en total sumaron algo más de un millón de votos. Estas elecciones también pusieron en evidencia la práctica desaparición de la conservadora Unión Nacional Obrista (UNO) que tras obtener el 25 por 100 de los votos en 1963, pasó a tener el 0,44 por 100 .

El elevado porcentaje de votación del Partido Popular Cristiano se debió al trasvase de votos del Partido Acción Popular que no participó, liderado por Fernando Belaúnde Terry, el que fuera derrocado de la presidencia de la República por el general Velasco en 1968. Para las elecciones de 1980 sí postuló a Belaúnde, logrando una holgada victoria con el 45,36 por 100 de los votos. La muerte de Víctor Raúl Haya de la Torre del Partido Aprista y la multiplicación de candidatos de izquierda colaboraron para dicho resultado al perder una importante cuota de votos ${ }^{69}$.

Las elecciones municipales de 1983 y las generales de 1985 confirmarian la tendencia de la conformación de tres grandes bloques ideológicos. Un primer sector de orientación conservadora en que compiten el Partido Popular Cristiano, de importante presencia en la capital, y el Partido Acción Popular. De otro lado, el sector socialdemócrata representado por el Partido Aprista Peruano y, finalmente, los grupos de izquierda reunidos en la Alianza de Izquierda Unida, que agrupa a sectores de todas las tendencias, marxistas y no marxistas. Al respecto, es importante poner de relieve que la unión de los partidos de izquierda ha potenciado desde entonces su presencia electoral, al punto que en las elecciones municipales de 1983 obtuvo el 29,52 por 100 de los votos, a tres puntos del primer lugar logrado por los apristas con el 32,67 por 100. La principal victoria constituyó la obtención de la Alcaldia de Lima, la más importante, ocupada hasta 1986

69 Una mayor información sobre el tema puede obtenerse en CHIRINOS SoTO, Enrique: La nueva Constitución y los Partidos Políticos. Lima, Centro de Documentación Andina, 1984. 
por Alfonso Barrantes Lingán. Por primera vez un marxista asüme la Alcaldía de la capital.

Las elecciones de 1985 dieron el triunfo al Partido Aprista y llevaron al poder a Alan García Pérez, con el 45,74 por 100 de los votos. Como mencionamos en un apartado anterior, la segunda vuelta no fue necesaria debido a la renuncia del candidato de Izquierda Unida, Alfonso Barrantes Lingán, que, con el 21,26 por 100 de los votos, fue el segundo candidato más votado.

Como señalamos, el carisma personal de los candidatos resulta decisivo en las elecciones, por ello BERNALES ha sostenido que «es lógico que en sociedades de este tipo, la ideología partidaria y los programas de gobierno cuenten electoralmente menos que el líder o el caudillo" ${ }^{70}$. En la práctica, el Presidente de la República es el Jefe de Estado, de Gobierno, del Partido y, considerando que en ambas elecciones ha obtenido una mayoría en las Cámaras, mantiene un gran poder sobre el Parlamento.

Finalmente, no se puede ignorar el fenómeno del terrorismo. A partir de 1980 el Perú empezó a sufrir los embates del terrorismo de extrema izquierda del Partido Comunista del Perú, más conocido como «Sendero Luminoso". La evolución del fenómeno se puede resumir en que actualmente es considerado como el principal problema del pais, superando inclusive a la larga crisis económica. El crecimiento y expansión del terrorismo ha provocado la declaración del estado de excepción en amplias zonas del territorio e, inclusive, la declaración del toque de queda en la capital por un período importante de tiempo. Hasta hoy, la respuesta de los gobiernos ha sido de carácter represivo, sin que se aprecien resultados importantes. Esta es una variable importante para definir la estabilidad del régimen actual; en la medida que el avance de la insurrección constituye un peligro, no sólo para la democracia, sino para la "seguridad nacional», la presencia militar en el escenario político puede nuevamente darse. Éste es reto de los próximos años. 